\title{
Charge Enhanced Contamination and Environmental Degradation of MISSE-6 SUSpECS Materials
}

\author{
JR Dennison, Amberly Evans, Danielle Fullmer and Joshua L. Hodges
}

\begin{abstract}
The effects of prolonged exposure to the LEO space environment and charge-enhanced contamination on optical, thermal, and electron emission and transport properties of common spacecraft materials have been investigated by comparing pre- and post-flight characterization measurements. The State of Utah Space Environment and Contamination Study (SUSpECS) deployed in March 2008 on board the Materials International Space Station Experiment (MISSE-6) payload, was exposed for 18 months on the exterior of the International Space Station (ISS), and was retrieved in September 2009. A total of 165 samples were mounted on three separate SUSpECS panels on the ram and wake sides on the ISS. Some samples, particularly those exposed to atomic oxygen in the ram direction, showed pronounced effects due to exposure. Biased samples for the charge-enhanced contamination study showed subtle variations in visible and infrared reflectivity.
\end{abstract}

Index Terms-Charging, contamination, space environment effects, materials.

\section{INTRODUCTION}

A cooperative, Utah-based project named SUSpECS (State of Utah Space Environment and Contamination Study) was developed as a flight experiment to study the effects of prolonged exposure to the space environment and chargeenhanced contamination on spacecraft materials. Utah researchers from the Utah State University (USU) Materials Physics Group (MPG), the USU Space Dynamics Laboratory (SDL) Contamination Control/Materials Chemistry Group, the ATK Space Systems Health Management Focus Group, and the USU Get-Away Special (GAS) Team built sample trays for flight on the MISSE-6 (Materials International Space Station Experiment) mission sponsored by Air Force Office of Scientific Research (AFOSR). The MISSE program objective

Research was supported by funding from USU Space Dynamics Laboratory, the NASA Solar Probe Mission through Johns Hopkins Applied Physics Laboratory, and a Utah State University Undergraduate Research and Creative Opportunities grant.

JR Dennison, Amberly Evans and Danielle Fullmer are with the Materials Physics Group in the Physics Department at Utah State University in Logan, UT $84322 \quad$ USA (e-mail: JR.Dennison@usu.edu, (amb.eva@aggiemail.usu.edu, danielle.fullmer@aggiemail.usu.edu).

Joshua L. Hodges is a Service Life Monitoring Program Manager with the T-38 Structural Analysis Group at Hill Air Force Base, Ogden, UT 81234 USA (email: joshua.hodges@hill.af.mil).

Color versions of one or more figures in this paper are available online at http://ieeexplore.ieee.org.

Digital object identifier . is to "characterize the performance of new prospective spacecraft materials when subjected to the synergistic effects of the space environment" [1]. The SUSpECS sample panels include pertinent materials and coatings selected and characterized by each group member for a comprehensive study of the effects of the low Earth orbit (LEO) space environment and contamination on electrical, mechanical, and optical properties of materials related to several on-going projects of high relevance to manned space exploration and other long duration space missions [2].

Sample material selections, conceptual design of the SUSpECS sample panels, and construction of the panels were completed during 2005, led by student researchers from the USU GAS Team. Design of the sample panels are described below, including a three tiered configuration intended to provide variable atomic oxygen and ultraviolet radiation exposure. The SUSpECS sample panels were delivered to Boeing in spring 2006 for integration with the panels contributed by other industry, university, and government investigators. The sample panels were installed into two standard MISSE “suitcase” pallets (PECs) that were powered and instrumented to record relevant space environmental parameters during the on-orbit exposure. The integrated payload was delivered to NASA Langley Research Center in summer 2006. The Shuttle flight STS-123 transported MISSE-6 to the ISS and deployed it on the ISS "back porch" in March 2008. MISSE-6 was returned to Earth in September 2009 and the SUSpECS sample trays were de-integrated from the MISSE PECs at NASA Langley Research Center in October 2009. Photographs of various aspects of the deployment and retrieval are shown in Ref [3].

\section{SUSPECS SAMPLE SETS}

\section{A. Sample Selection for Materials Studies}

The samples for flight were carefully chosen to provide needed information for several different ongoing studies and to cover a broad cross-section of prototypical materials used on the exteriors of spacecrafts. Table I lists the samples selected for inclusion on the SUSpECS sample panels.

Results reported here focus on the comparison of two specific sets of materials samples. The first comparison focuses on six sets of four identical samples [Au, Al, carbonloaded polyimide (Dupont Black Kapton ${ }^{\mathrm{TM}}$ 100XC), and carbon-loaded polyester (Sheldahl Thick Film Black)]. Two sample sets were located on the top and bottom tiers of a 
three-tiered sample panel designed to provide variable atomic oxygen and UV exposure. The four other sample sets were located on the wake side sample panel, with each set held at constant bias for the duration of the flight. The biased sample configuration was designed to approximate typical conditions of materials subject to charge-enhanced contamination due to spacecraft charging by actively biasing samples to low positive and negative voltages.

The second comparison reported here focused on four materials [carbon-loaded polyimide, aluminized polyester (Dupont Mylar ${ }^{\mathrm{TM}}$ ), $\mathrm{Al}_{2} \mathrm{O}_{3}$ (sapphire), and $\mathrm{SiO}_{2}$ (quartz)] that showed varying degrees of environmentally-induced changes in optical properties. Samples of each material on the wake and three-tiered sample panels were exposed to a complex environment during the flight. Identical witness samples were also exposed to a simulated subset of the environment in the Characterization of Combined Orbital Surface Effects (CCOSE) space environment test chamber at the USAF Arnold Engineering Development Center (AEDC) to mimic the space exposure profile [3-5]. The primary optical characterization methods employed for the comparison were UV/VIS/NIR and FTIR transmission of the sapphire and quartz and UV/VIS/NIR reflectance of the polyimide and polyester. Comparison of pre-flight, post-flight, and simulated exposure samples served two primary purposes: (i) to investigate the validity of simulated environmental testing methods and (ii) to help distinguish the effects of specific components of the complex space environment that samples were simultaneously exposed to during the flight. Initial results of the CCOSE tests were reported in Ref. [3].

Four additional SUSpECS test programs with direct relevance to spacecraft charging issues are briefly outlined below. These are studies of electron emission and resistivity of typical spacecraft materials, CRRES materials charging and contamination, ISS materials charging and contamination, and the effects of contamination on FPMU materials.

Electron-, ion-, and photon-induced electron emission yield curves, crossover energies and emission spectra, resistivity, dielectric strength, optical and electron microscopy, UV/VIS/NIR reflection spectroscopy, and emissivity were tested for pre-flight SUSpECS samples in their pristine conditions. The majority of the test samples have already undergone pre-flight analysis during an ongoing seven year study of the electron emission [6-11] and resistivity properties [1], [7], [12-14] of spacecraft materials sponsored by the NASA Space Environments and Effects Program. Preliminary ground-based studies at USU have shown that contamination can produce dramatic changes in electron emission that can lead to severe charging effects under certain circumstances $[15,16]$. A preliminary study of the effects of contamination on resistivity using the charge storage method is underway at USU. Comparison with post-flight analysis will provide the first extensive tests of space environment exposure and contamination on electron emission properties and resistivity.

Several types of samples were flown aboard the CRRES satellite [17] as part of a study of charging induced arcing [18]. The samples were the subject of detailed resistivity tests using the charge storage method [19] and very successful
Table I. SUSpECS samples.

\begin{tabular}{|c|c|c|}
\hline Material & Source & \#Sample: \\
\hline Kapton (PI) on Aluminum & Sheldahl & 4 \\
\hline Teflon (PTFE) on Aluminum & Sheldahl & 3 \\
\hline Mylar (PET) on Aluminum & Sheldahl & 3 \\
\hline Nylon $6 / 6$ & McMaster-Carr & 1 \\
\hline $\mathrm{SiO} 2$ (Fused Quartz) & UQG Optics & 3 \\
\hline Al2O3 (Sapphire) & UQG Optics & 2 \\
\hline Germanium on Kapton & Sheldahl & 1 \\
\hline Anodized Aluminum (Chromic Acid Etch) & NASA / MSFC & 1 \\
\hline Anodized Aluminum (Sulfuric Acid Etch) & NASA / MSFC & 1 \\
\hline UV AR-coated Ce-doped Cover Glass & Thales & 3 \\
\hline FR4 Printed Circuit Board (PI Composite) & CRRES NASA / JPL & 3 \\
\hline CV-1147 RTV on Copper & NusivBoeing & 1 \\
\hline DC93-500 RTV on Copper & Dow-Corning/Boeing & 2 \\
\hline Zinc Oxide White Paint (Z93-C55) & Alion & 3 \\
\hline Borosilicate BK7 Glass & UQG Optics & 3 \\
\hline Gold (99.99\% Purity) & ESPI & 7 \\
\hline Aluminum (99.999\% Purity) & ESPI & 7 \\
\hline 316 Stainless Steel & McMaster-Carr & 2 \\
\hline OFHC Copper (99.9\% Purity) & McMaster-Carr & 1 \\
\hline Silver (99.999\% Purity) & United Materials & 3 \\
\hline g-C (Graphitic Amorphous Carbon) on Copper & Arizona Carbon Foil & 1 \\
\hline Aquadag (microcrystalline C) on Copper & LADD Research & 2 \\
\hline 100XC Black Kapton & Sheldahl & 6 \\
\hline Thick Film Black & Sheldahl & 6 \\
\hline Inconnel on Silver on Teflon on ITO & Sheldahl & 1 \\
\hline ITO on Teflon on Silver on Inconel & Sheldahl & 1 \\
\hline Gold(2um)/Nickel(2um) on 316 Stainless Steel & Gold Plating Services & 3 \\
\hline $\mathrm{Rh}(2 \mathrm{um}) / \mathrm{Ni}(2 \mathrm{um})$ on 316 Stainless Steel & Gold Plating Services & 3 \\
\hline $\mathrm{Au}(2 \mathrm{um}) / \mathrm{Rh}(2 \mathrm{um})$ on 316 Stainless Steel & Gold Plating Services & 3 \\
\hline $\mathrm{Au}(2 \mathrm{um}) / \mathrm{Rh}(2 \mathrm{um}) / \mathrm{Ni}(2 \mathrm{um})$ on 316 Stainless Steel & Gold Plating Services & 3 \\
\hline Reinforced Carbon Nano-fiber/RS-3 Cyanate Ester Composite & SDL GIFTS Satellite & 2 \\
\hline ASN720 Oxide Ceramic-Metal Composite & COIC/ATK Thiokol & 5 \\
\hline S200 Nonoxide Ceramic-Metal Composite & COIC/ATK Thiokol & 5 \\
\hline Thiokol Graphite Epoxy Foil - No Hole & ATK Thiokol & 5 \\
\hline Thiokol Graphite Epoxy Foil - With Hole & ATK Thiokol & 5 \\
\hline Thiokol Carbon-Carbon Composite \#1 & ATK Thiokol & 5 \\
\hline Thiokol Carbon-Carbon Composite \#2 & ATK Thiokol & 5 \\
\hline Thiokol Fiber-Filled Carbon-Carbon Composite & ATK Thiokol & 5 \\
\hline Thiokol Carbon-Phenolic Carbon-Carbon Composite & ATK Thiokol & 5 \\
\hline S400 Nonoxide Ceramic-Metal Composite & COIC/ATK Thiokol & 2 \\
\hline S200H Nonoxide Ceramic-Metal Composite & COIC/ATK Thiokol & 2 \\
\hline S300 Nonoxide Ceramic-Metal Composite & COIC/ATK Thiokol & 2 \\
\hline
\end{tabular}

modeling of their pulsing history during the CRRES flight $[12,20]$. The MISSE-6 tests will support modeling of the effects of prolonged space exposure during the CRRES flight. Relevant samples include Kapton ${ }^{\mathrm{TM}}$ (PI), Teflon ${ }^{\mathrm{TM}}$ (PTFE), Mylar $^{\mathrm{TM}}$ (PET), FR4 PC board (PI composite) material, alumina $\left(\mathrm{Al}_{2} \mathrm{O}_{3}\right)$, and silicon dioxide $\left(\mathrm{SiO}_{2}\right)$.

A study of the electron emission and resistivity properties of a set of materials used to construct the ISS has been performed. This includes both basic materials [Au, Al, 316 SS, anodized Al (chromic acid etch), anodized Al (sulfuric acid etch), Kapton ${ }^{\mathrm{TM}}$, Dupont Black Kapton ${ }^{\mathrm{TM}}$, and UV ARcoated Ce-doped cover glass] [7] and a study of two RTV materials (DC93-500 and CV-1147) thought to be key contaminants of the ISS solar arrays [11]. Comparison of analysis of these MISSE-6 samples with pre-flight testing will provide valuable information for modeling the ISS spacecraft charging as the station ages.

A study was undertaken of the electron emission and resistivity properties of a set of materials used to construct the Floating Potential Measurement Unit (FPMU). The FPMU is an instrument designed and built at SDL for use on the ISS $[21,22]$ used to monitor spacecraft charging on the ISS [23-26] through plasma measurements. The sample set includes both basic materials used to construct the FPMU [Au, $316 \mathrm{SS}$, Aquadag ${ }^{\mathrm{TM}}$ ] and two RTV materials (DC93-500 and CV1147) thought to be potential key contaminants of the FPMU $[7,27]$. The electron emission properties and resistivity of the materials, and how these properties change with exposure to 


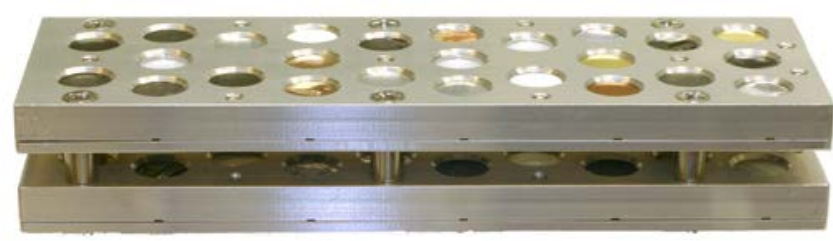

(a)

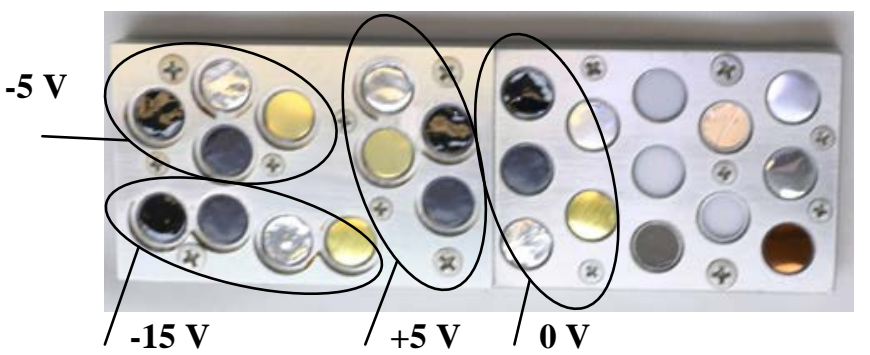

(c)

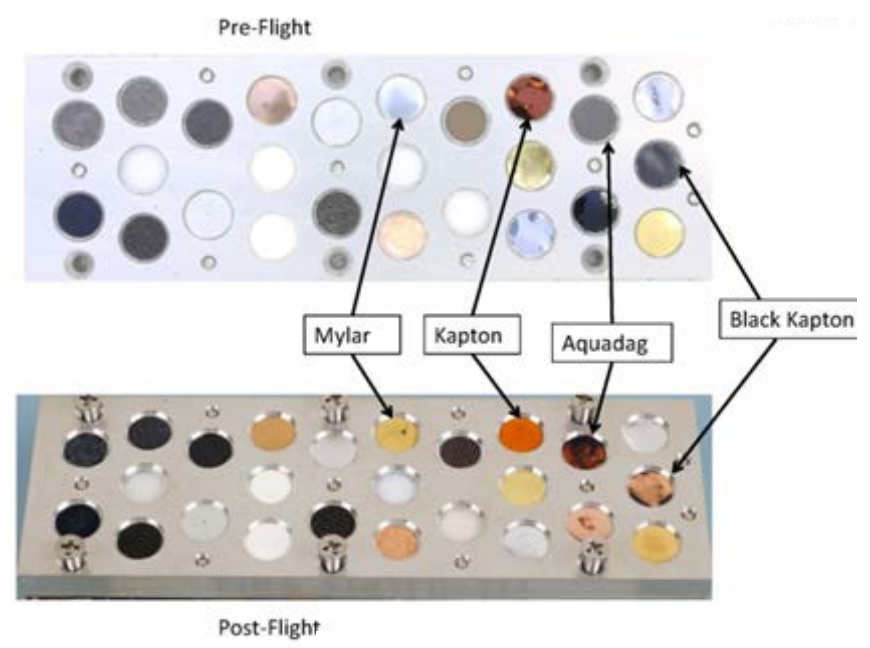

(b)

Figure 1. Configuration of $5 \mathrm{~cm} \times 30 \mathrm{~cm}, 78 \mathrm{~cm}^{2} S U S p E C S$ sample panels. (a) Side view of ram side SUSpECS I sample panels. All samples are passive experiments held at ground potential. A three tiered configuration design is used with 25 samples exposed on each tier. (b) Pre- and post-flight photographs showing locations of samples shown in Figure 2. (c) Wake side SUSpECS II sample panel. Thirteen exposed samples at right are passive experiments held at ground potential. The three sub-panels at left each contain four identical samples held at + 5 VDC, -5 VDC and -15 VDC, respectively.

the space environment and accumulation of contamination, are critical to the precise determination of the surface potentials. Comparison of analysis of these MISSE-6 samples with preflight testing will provide valuable information for modeling the FPMU electron emission and the instrument effectiveness in monitoring the ISS potential as the station ages.

Additional studies of critical thermal control and optical coating materials for the USU SDL Geosynchronous Imaging Fourier Transform Spectrometer (GIFTS) composites, mechanical and thermal properties of ATK Thermal Protection Systems and Lightweight Structure Systems materials, and NASA Solar Probe Mission composite and heat shield materials have been described elsewhere [2].

\section{B. Space Environment Exposure of Samples}

The SUSpECS study exposed three test panels of materials-SUSpECS I, II and III-to the LEO environment for $\sim 18$ months. Environmental monitoring on board the MISSE-6 suitcases included temperature monitoring at a number of points on each pallet. Atomic oxygen (AO) exposure was monitored by the degradation of Kapton ${ }^{\mathrm{TM}}$ strips [28-30] placed on the 6A and 6B PECS; the AO fluence was $2 \cdot 10^{21}$ atoms $/ \mathrm{cm}^{2}$ with an estimated variation of $\sim 5 \%$ [31]. Solar ultraviolet (UV) exposure as a function of time was monitored with UV photodiodes at several locations. Absolute absorbed radiation dosage was monitored with several thermoluminescent detectors (TLD). The Air Force MISSE-6 experiment also monitored the electron flux in the $0-200 \mathrm{eV}$ regime. Specific details of space environment exposure for SUSPECS sample holders and CCOSE space simulation tests are discussed in Ref. [3].

\section{Ram Side Sample Panel Design and Configuration}

One sample panel shown in Figure 1(a), SUSpECS I, was mounted on PEC 6A on the ram side of the ISS, with enhanced exposure to atomic oxygen. These experiments were all passive LEO exposure experiments. Details of the sample mount are given in Ref. [3]. This panel included 981.3 $\mathrm{cm}$ diameter (1 $\mathrm{cm}$ exposed diameter) conducting and insulating samples held at ground potential. The specific samples are identified in Table I.

The ram-side sample holder was configured so that four stacked sample tiers were exposed to $\mathrm{AO}+\mathrm{UV}, \mathrm{AO}$ alone (2 sets), and no AO or UV. All these materials were tightly seated in a metal tray. The sample geometry was designed such that the sides of each tier were masked, allowing only front face exposure and forcing any diffusion into a onedimensional regime. This will permit one-dimensional depth profiling of the materials to evaluate the effects of environmental exposure. The outermost tier experienced the fullest exposure to all of the variables of LEO environment, most importantly atomic oxygen and ultraviolet radiation. The lower tiers, being shielded by the outermost layer, did not have exposure to ultraviolet radiation. Due to a gap between the second and third tiers in the stacked configuration, the second and third tiers were exposed to reduced fluxes of atomic oxygen. The lowest tier was fully shielded from ultraviolet radiation and atomic oxygen by the third tier. In addition to the MISSE-6 onboard monitors of UV and AO flux, the cumulative fluence at various points on SUSpECS was also monitored. AO exposure was monitored [30] by the relative oxidation of high purity Ag strips [28], [29], [32] and the degradation of Kapton ${ }^{\mathrm{TM}}$ strips [28], [29] placed on the frame of each tier. UV exposure is monitored by the discoloration of $1.3 \mathrm{~cm}$ diameter, $1 \mathrm{~cm}$ thick borosilcate BK7 glass sample disks mounted on each tier as color centers are formed by the UV radiation.

\section{Wake Side Sample Panels Design and Configuration}

SUSPECS II and III sample panels faced the wake side of the ISS on PEC 6B, with less exposure to atomic oxygen. SUSpECS III was fully passive with 25 mounted in a sample holder like the bottom tier of SUSpECS I. SUSpECS II had 13 $1.3 \mathrm{~cm}$ diameter passive exposure test samples held at ground, 

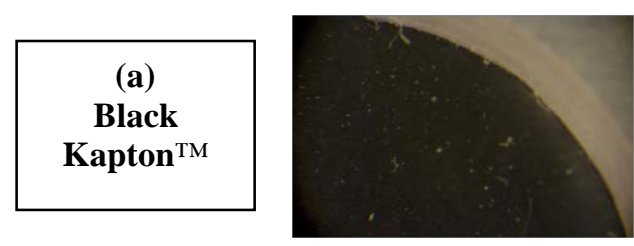

(b) Aquadag
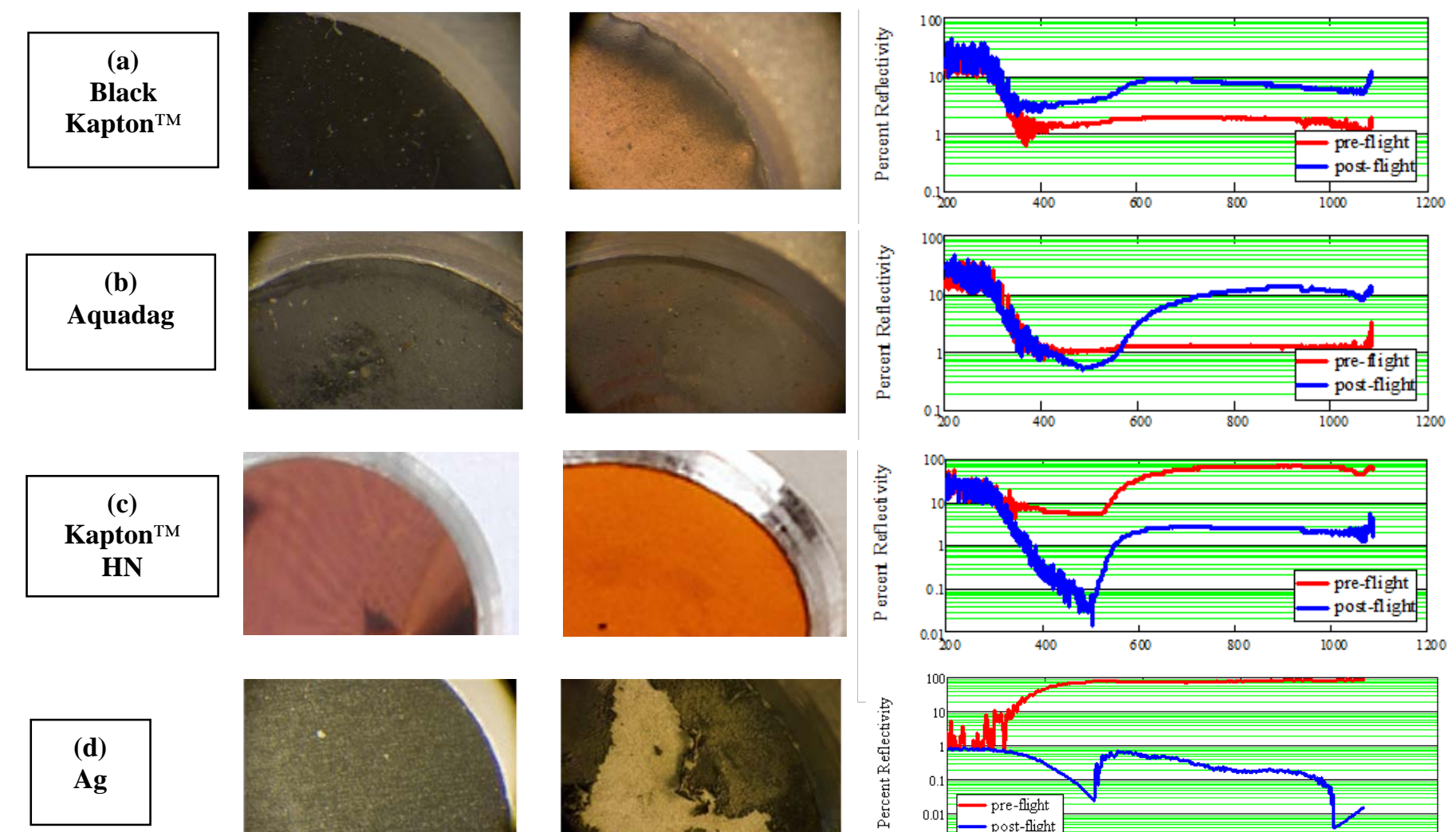

\begin{tabular}{|c|}
\hline$(e)$ \\
VDA coated \\
Mylar ${ }^{\mathrm{TM}}$ with \\
micro- $^{\text {meteoroid }}$ \\
impact \\
\hline
\end{tabular}
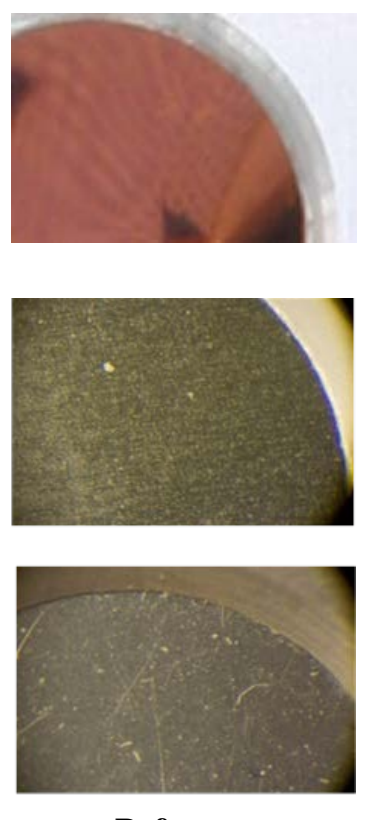

Before
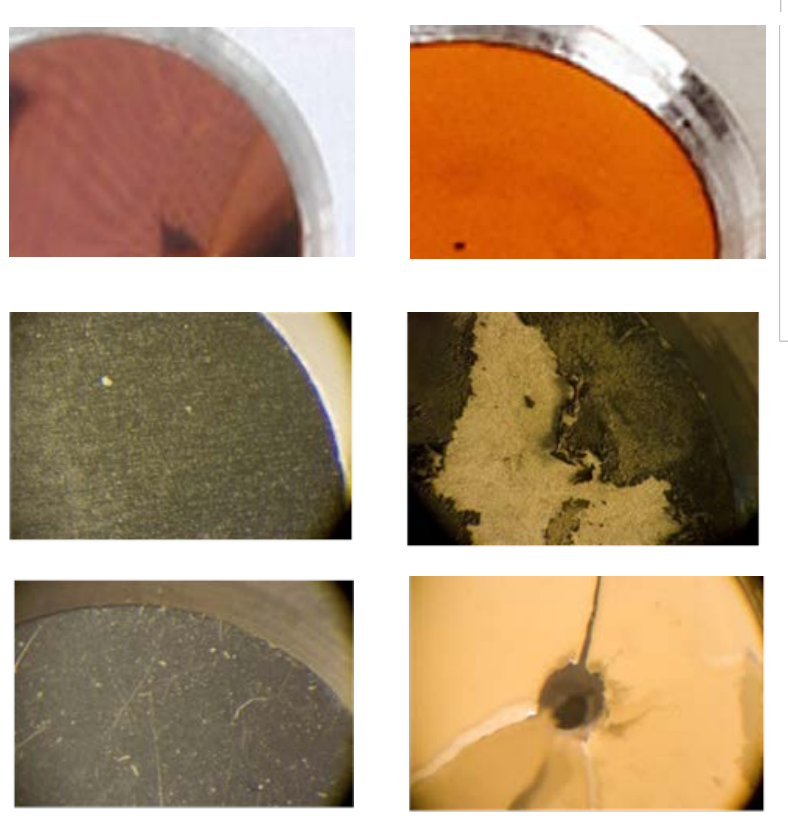

After
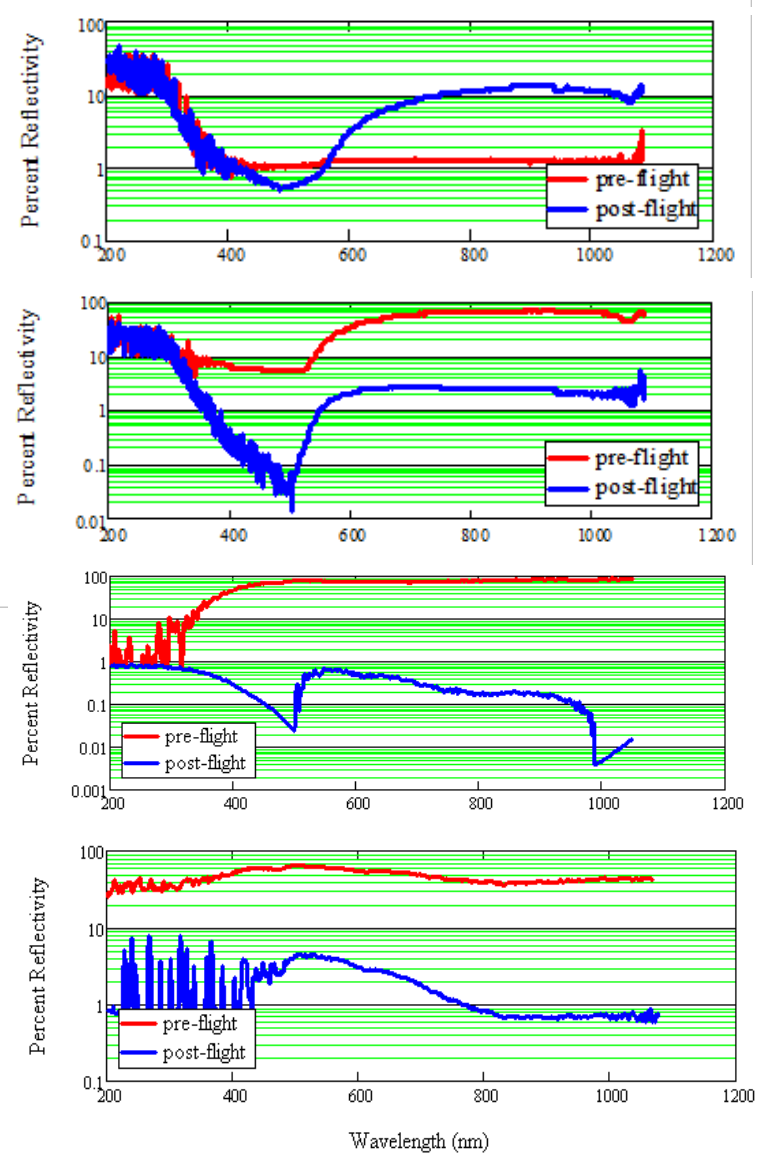

Figure 2. Comparison of pre- and post-flight photographs and UV/VIS/NIR reflectance spectra of samples from SUSpECS II on the ram side with high $\mathrm{AO}$ exposure. (a) Black Kapton ${ }^{\mathrm{TM}} 100 \mathrm{XC}$, (b) Aquadag colloidal graphite coating on Cu substrate, (c) Kapton ${ }^{\mathrm{TM}}$ HN and (d) bulk Ag. (e) Vapor-deposited Al coated. Note the apparent micrometeoroid impact and the full AO oxidation of the Al of the VDA coated Mylar ${ }^{\mathrm{TM}}$ sample. Sample locations are shown in Figure 1(b).

as shown in the right hand side of Figures 1(c). Additional grounded samples were mounted underneath the exposed samples. The specific samples are identified in Table I.

SUSPECS II also had the sole active experiment. There were three separate test sub-panels of $\sim 13 \mathrm{~cm}^{2}$, each with four conducting samples mounted on SUSpECS II, as shown in Figures 1(c). These three sub-panels were held at +5 VDC, -5 VDC and -15 VDC, respectively, for the full duration of the flight. Although these sample potentials could not be directly verified during flight, pre- and post-flight continuity and isolation tests confirmed intact circuitry. Voltages for the subpanels were provided by the ISS through the MISSE- 6 bus. Resistors and fuses were mounted in series with each subpanel to limit arcing currents. A grounded sample guard was positioned above the three sub-panels to minimize possible contact with biased sub-panels by astronauts during EVAs. The beveled edges of the sample clamp and guard shield were designed to minimize fringing fields to provide nearly parallel voltage contours typical of larger biased samples, as shown by field simulations (see Figure 3 in Ref [2]).
The biased sample configuration was designed to approximate typical conditions of materials subject to spacecraft charging. Based on a space plasma environment current density of $\sim 10 \mathrm{nA}-\mathrm{cm}^{-2}$, the three biased plates collectively drew $<1 \mu \mathrm{A}$. The positive test bias was chosen as $+5 \mathrm{~V}$. Positively charged components will typically charge to only a few volts positive [33], since low energy emitted electrons will be re-attracted to a positively charged surface and the majority of emitted electrons have energies below $\sim 5$ $\mathrm{eV}$ [6]. By contrast, negatively charged materials can charge to large voltages, since emitted electrons are repelled from the charged surface and therefore do not self-limit charging, as is the case for positive biasing [6]. Biases of $-5 \mathrm{~V}$ and $-15 \mathrm{~V}$ were chosen as representative of modest and more extreme negative charging.

\section{TESTING}

\section{A. Materials Testing}

Comparison of post-flight analysis of these MISSE-6 
(a) Au

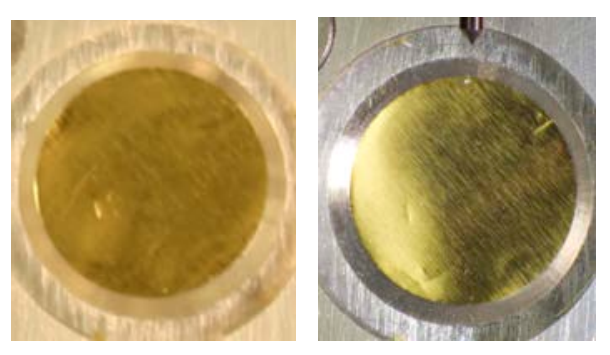

(b) Al

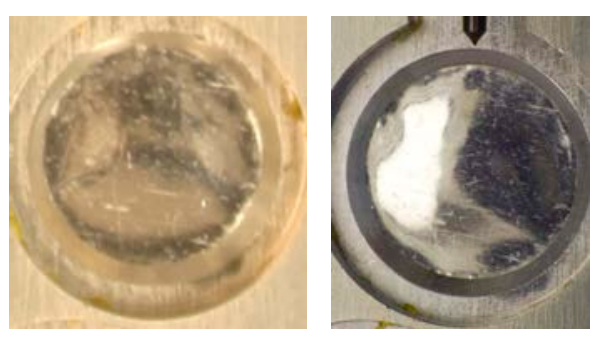

(c) Black Kabton 100XC
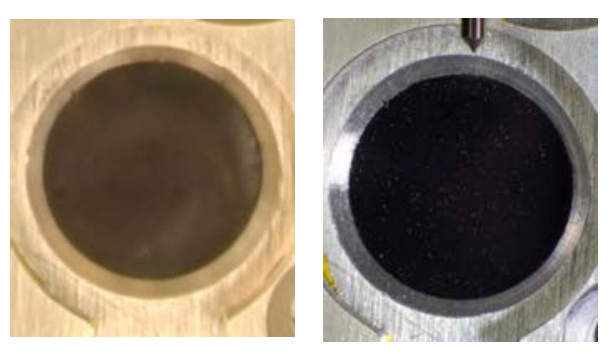

(d) Thick Film Black

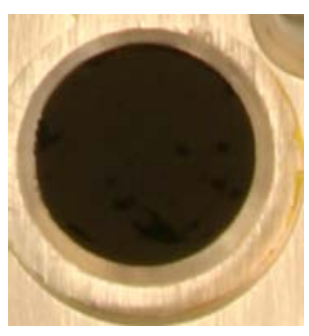

Before

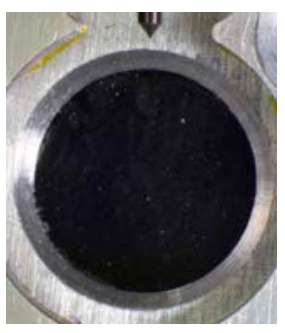

After
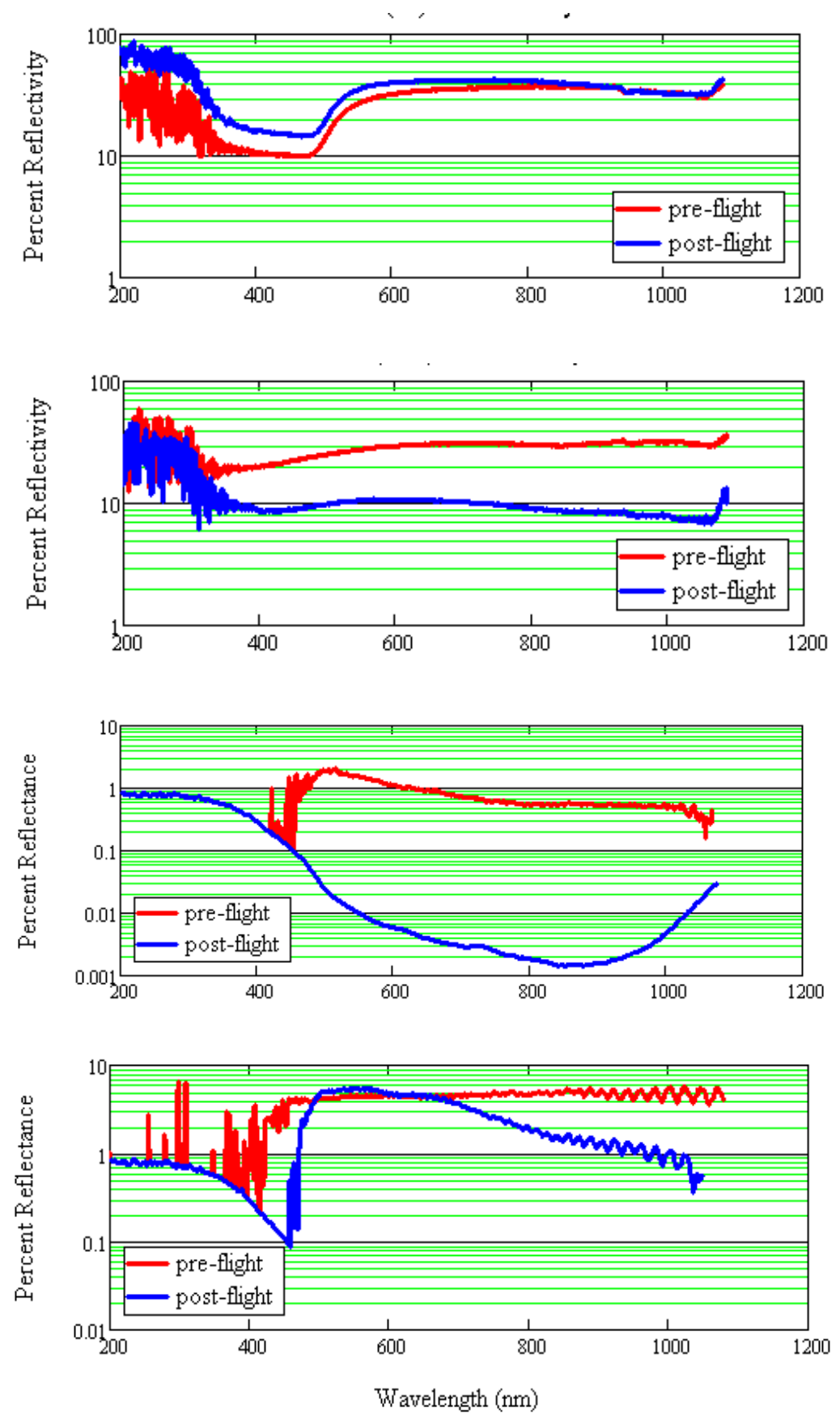

Figure 3. Comparison of pre- and post-flight photographs and UV/VIS/NIR reflectance spectra of $-5 \mathrm{~V}$ charge samples with wake exposure on SUSpECS I. (a) Au, (b) Al, (c) Carbon-filled polyimide or Black Kapton ${ }^{\mathrm{TM}} 100 \mathrm{XC}$, (d) Carbon-filled PET or Thin Film Black.

samples with pre-flight testing will be valuable in trying to identify and model materials degradation and aging and the effects of prolonged space exposure on the samples. All samples will undergo an extensive series of pre-flight and post-flight tests to characterize the materials properties, including surface morphology [optical microscopy, scanning electron microscopy (SEM), scanning tunneling microscopy (STM)], chemical compositions, [standard suite of chemical analysis tests such as HPLC, Auger Electron Spectroscopy (AES), Secondary Ionization Mass Spectroscopy (SIMS) and X-Ray Photoelectron Spectroscopy (XPS)], optical (IR-VISUV attenuated total (ATR), specular and/or diffuse reflection spectroscopy [34]), thermal (thermal expansion, thermal emissivity and absorptivity), and outgassing.

\section{B. Electrical Properties of Spacecraft Materials}

The electron emission properties and resistivity of many SUSpECS materials will be tested. Specifically, the materials will be tested for resistivity and dielectric strength, and for electron-, ion- and photon-induced electron emission yield curves and emission spectra. Details of the testing procedures are described in Refs. [7,35]. Much of the pre-flight testing has already been done in conjunction with previous studies.

The electron emission and transport properties of materials are key parameters in determining the likelihood of deleterious spacecraft charging effects $[7,33,36,37]$ and are essential in 
modeling these effects with engineering tools such as the NASA NASCAP-2K [38-40], SPENVIS, and MUSCAT [41] codes. The SUSpECS studies of electron emission and resistivity will extend more than a decade of research in the field by the USU MPG [3,6-13,19,40,42-43].

Recent work [13,44] found that dissipation of charge accumulated on thin film insulating spacecraft surfaces during on-orbit conditions is substantially slower than predicted using resistivity values acquired by standard ASTM methods [45]. This can result in charge dissipation on the order of days to months rather than minutes to hours [12]. More appropriate methods to measure charge storage decay have been developed. Apparatus to measure the decay rate of charge deposited on the surface of thin film insulators have been designed and built at USU in conjunction with an on-going NASA research project with JPL [14] and the USU electron emission test chamber [46]. Comparison of pre- and postflight analysis of SUSpECS samples using these methods will provide a better understanding of modifications to these long decay times as a result of space exposure and contamination.

\section{Pre- and Post-Flight Comparisons}

Measurements of the optical microscopy and normal specular UV/VIS/NIR reflectance of selected pre- and postflight samples that exhibited significant changes are presented in Figures 2 and 3. These preliminary results can be compared to assess on-flight degradation.

Figure 2 shows results for five samples from SUSpECS II on the ram side with high AO exposure. The first three materials-(a) Black Kapton ${ }^{\mathrm{TM}}$ 100XC, (b) Aquadag ${ }^{\mathrm{TM}}$ colloidal graphite coating on $\mathrm{Cu}$ substrate, and (c) Kapton ${ }^{\mathrm{TM}} \mathrm{HN}$-all exhibit significant material loss and changes in color evident in both the photographs and the reflection spectra. Presumably, these changes are due to strong AO oxidation of these carbon-based materials. The bulk Ag sample (d) also exhibits significant oxidation. Work is underway to compare the results of the Kapton ${ }^{\mathrm{TM}} \mathrm{HN}$ and $\mathrm{Ag} \mathrm{AO}$ changes, to investigate whether the Ag represents a viable alternative as an AO fluence sensor. The changes observed in the vapordeposited Al coated Mylar ${ }^{\mathrm{TM}}$ (PET) sample (e) are perhaps the most dramatic. It appears that the $\mathrm{AO}$ oxidation has completely removed the $\sim 100 \mathrm{~nm}$ thick VDA coating. There is also what appears to be a micrometeoroid impact site.

\section{Charge-Induced Contamination Study}

A primary focus of SUSpECS is the study of the effects of contamination on the accumulation, re-emission, and dissipation of charge from spacecraft surfaces and on the resulting changes in electron emission and resistivity of spacecraft materials [40]. This project also investigates the effects of charging on contamination rates. Synergistic phenomena in the space environment (e.g., charging, contamination, UV exposure, atomic oxygen) can cause dramatic changes in material surface properties and performance $[3,47]$. Thin contaminant layers readily change the optical $[34,42,48]$ and electronic properties $[15,16]$ of surfaces, and often result in long-term degradation of the optical, thermal control, or electronic performance of spacebased sensors and components. For example, plasma diagnostic instrumentation (such as Langmuir and plasma impedance probes) requires stable surface conductivity and charging properties, which is altered by contamination [42]. Further, at geosynchronous orbits, high spacecraft charging potentials (typically tens of kilovolts) and long Debye lengths can actually accelerate surface contamination rates by electrostatic re-attraction of ionized outgassed or vented molecules to the negatively charged satellite [49]. Accelerated contamination rates can affect the long-term performance of optical, thermal control, or solar panel surfaces. Also the performance of new high efficiency multijunction solar cells is more susceptible to current loss caused by contamination than conventional single junction cells [34].

Studies at USU have shown that very thin layers of contamination-even a few monolayers-can potentially cause significant changes in electron emission properties that can dramatically affect the charging of satellites and can lead to catastrophic charging effects under certain circumstances [15], [16]. Figure 5 in Ref. [16] shows the threshold differential charging of clean $\mathrm{Au}$ and carbon-contaminated $\mathrm{Au}$ surfaces on a hypothetical satellite in GEO orbit. However, little direct information is available on the effects of sample deterioration and contamination on the electron emission and resistivity of materials flown in space.

The comparisons presented in Fig. 3 focus on six sets of four identical samples [Au, $\mathrm{Al}$, carbon-loaded polyimide, and carbon-loaded polyester]. Two sample sets were located on the top and bottom tiers of a three-tiered sample panel designed to provide variable atomic oxygen and UV exposure. The four other sample sets were located on the wake side sample panel, with sets biased for the duration of the flight at 0 VDC, +5 VDC, - 5 VDC, and -15 VDC, respectively.

Comparison of pre- and post-flight photographs of the four biased wake sample sets (Figure 5), show no significant changes are apparent in the visible, in marked contrast to extensive sample modifications observed for some ram samples (Figure 3). Comparison of pre- and post-flight NIR/VIS reflectivity spectra provide a more sensitive test and are consistent with minimal changes observed in the visible region in the photographs. All four samples show little change for wavelengths less than $300 \mathrm{~nm}$ to $450 \mathrm{~nm}$. Au shows minimal change over the full spectral range; minimal changes due to contamination would be expected for the inert $\mathrm{Au}$ surfaces [34]. The other three samples show reduction of already low reflectivity for most wavelengths $>400 \mathrm{~nm}$. Variations of the magnitude of the reduced reflectivity with wavelength—especially in the NIR/VIS above $400 \mathrm{~nm}$-are more consistent with wavelength dependant absorption from contamination layers than from the generally uniform reductions in reflectivity that result from surface roughening [34]. Thin film interference fringes observed at wavelengths above $\sim 850 \mathrm{~nm}$ for the carbon-loaded polyester samples suggest there is a fairly uniform $\sim 20 \mu \mathrm{m}$ thick polyester film above the highly absorbing carbon-loaded bulk [34]. The fact that similar fringes are still present in the post-flight spectrum suggests that this layer was not significantly modified during space exposure. The reduction in reflectivity for the postflight film is consistent with formation of a thin film 
contaminate layer. While all the observed spectral changes are consistent with formation of a thin film absorbing contamination layer with preferential absorption in the NIR, further measurements and analysis are required to more fully determine the changes in materials properties that result from charge-enhance contamination.

\section{FUTURE WORK}

Work on analysis of the effects of space environment exposure on the 168 samples has only begun. Measurements of optical and electron microscopy, reflectivity, FTIR, emissivity, mass loss, electron-, ion- and photon-induced electron emission, photoyield, AES, photoemission, and variable angle UV/VIS/NIR reflectivity will continue. Work will also progress in collaboration with the AEDC space simulation facility to understand the origins of these effects and quantify their impacts.

\section{ACKNOWLEDGMENT}

Research on SUSpECS was supported by funding from USU Space Dynamics Laboratory, the NASA Solar Probe Mission Program through Johns Hopkins Applied Physics Laboratory, and a Utah State University Undergraduate Research and Creative Opportunities grant. A special thanks goes to the USU Get-Away-Special Team-especially Jeff Duce and Josh Hodges-for their critical role in the design and construction of SUSPECS. We gratefully acknowledge the Air Force Office of Scientific Research (AFOSR) that sponsors the MISSE program and NASA that provides transportation to and from the ISS aboard the Space Shuttle. Gary Pippin, Steve Hahn, and the team at Boeing provided invaluable support for the project and as did the team at NASA Langley Research Center who integrated and deintegrated the SUSpECS sample panels into the MISSE-6 Passive Experiment Containers (PECs). We also have profited from useful discussion with M.R. Carruth, Jr. and T. Schneider at NASA Marshal Space Flight Center and John Alred at Boeing about ISS materials; Charles Swenson in the Electrical and Computer Engineering Department at USU about FPMU materials; Clint Thompson and Jim Burns at ATK Space Systems; and A. Robb Frederickson and Nelson W. Green at the Jet Propulsion Laboratory about CRRES materials. Andrew Auman performed the SimION electric field simulations. Sarah Barton, Jodie Corbridge Guthrie, Ryan Hoffmann and Jonathan Abbott of the USU Materials Physics Group helped with various characterization measurements and sample preparation. Jim Dyer at USU Space Dynamics Laboratory was instrumental in characterization measurements and sample preparation and assembly. John Prebola, Dustin Crider and Daniel Crews with the Aerospace Testing Alliance at Arnold Air Force Base collaborated on ground test chamber simulations for space degradation of samples.

\section{REFERENCES}

[1] "Material International Space Station Experiment (MISSE)," http://misse1.larc.nasa.gov/ ,March 24, 2005.
[2] J.R. Dennison, J. L. Hodges, J. Duce, and A. Evans, "Flight Experiments on the Effects of Contamination on Electron Emission of Materials," Proc. of $1^{\text {st }}$ AIAA Atmospheric and Space Environments Conf., 2009, Paper AIAA-2009-3641.

[3] J.R. Dennison, A. Evans, D. Fullmer, and J. L. Hodges, "Charge Enhanced Contamination and Environmental Degradation of MISSE-6 SUSpECS Materials," $11^{\text {th }}$ Spacecraft Charging Tech. Conf., (Albuquerque, NM, September 20-24, 2010).

[4] J. L.Prebola, , D. H. Crider, , D. S.Crews, "Evaluation of Enhancements to the AEDC Combined Space Environment Chamber", Proc. of $45^{\text {th }}$ AIAA Aerospace Sci. Meeting, Reno, NV, January 2007, Paper AIAA2007-0092.

[5] K. Hohman, L. B. Olsen, T. R. Brogan, J. L.Prebola, J. A. Stuckey, "Development of an Atomic Oxygen Source for Space Simulation Applications", Proc. of $46^{\text {th }}$ AIAA Aerospace Sci. Meeting, Reno, NV, January 2008, Paper AIAA-2008-0461.

[6] N. Nickles, R.E. Davies, J.R. Dennison, "Applications of Secondary Electron Energy- and Angular-Distributions to Spacecraft Charging," Proc. of $8^{\text {th }}$ Spacecraft Charging Tech. Conf., (AFRL Sc. Center, Hanscom AFB, MA, USA), 2000.

[7] J.R. Dennison, C.D. Thomson, J. Kite, V. Zavyalov and, J. Corbridge, "Materials Characterization at Utah State University: Facilities and Knowledgebase of Electronic Properties of Materials Applicable to Spacecraft Charging," Proc. of $8^{\text {th }}$ Spacecraft Charging Tech. Conf., (NASA Marshall Space Flight Center, Huntsville, Al, October 2003).

[8] J.R. Dennison, W.-Y. Chang, N. Nickles, J. Kite, C.D. Thomson, J. Corbridge and C. Ellsworth, Final Report Part II1: Materials Reports, NASA Space Environments and Effects Program, "Electronic Properties of Materials with Application to Spacecraft Charging,” September 2002. Published by NASA electronically at http://see.msfc.nasa.gov/scck/.

[9] J.R. Dennison, C. D. Thomson, and A. Sim, "The effect of low energy electron and UV/VIS radiation aging on the electron emission properties and breakdown of thin-film dielectrics," Proc. of $8^{\text {th }}$ IEEE Dielectrics and Electrical Insulation Society (DEIS) International Conf. on Solid Dielectrics (ICSD), pp. 967-971, IEEE, Piscataway, NJ, 2004.

[10] C.D. Thomson, V. Zavyalov, and J.R. Dennison, "Instrumentation for Studies of Electron Emission and Charging from Insulators," Proc. of $8^{\text {th }}$ Spacecraft Charging Tech. Conf., (NASA Marshall Space Flight Center, Huntsville, Al, October 2003).

[11] C.D. Thomson, V. Zavyalov, J.R. Dennison and J. Corbridge, "Electron Emission Properties of Insulator Materials Pertinent to the International Space Station," Proc. of $8^{\text {th }}$ Spacecraft Charging Tech. Conf., (NASA Marshall Space Flight Center, Huntsville, Al, October 2003).

[12] J.R. Dennison, A.R. Frederickson and P. Swaminathan, "Charge Storage, Conductivity and Charge Profiles of Insulators As Related to Spacecraft Charging," Proc. of $8^{\text {th }}$ Spacecraft Charging Tech. Conf., (NASA Marshall Space Flight Center, Huntsville, Al, October 2003).

[13] A.R. Frederickson and J.R. Dennison, "Measurement of Conductivity and Charge Storage in Insulators Related to Spacecraft Charging,” IEEE Trans. Nuclear Sci., vol, 50, no. 6, pp. 2284-2291, 2003.

[14] P. Swaminathan, A.R. Frederickson, J.R. Dennison, A. Sim, J. Brunson and E. Crapo, "Comparison of Classical and Charge Storage Methods for Determining Conductivity of Thin Film Insulators," Proc. of $8^{\text {th }}$ Spacecraft Charging Tech. Conf., (NASA Marshall Space Flight Center, Huntsville, Al, October 2003).

[15] R.E. Davies and J.R. Dennison, "Evolution of Secondary Electron Emission Characteristics of Spacecraft Surfaces,” J. Spacecraft and Rockets, vol. 34, pp. 571-574, 1997.

[16] W.Y. Chang, J.R. Dennison, J. Kite and R.E. Davies, "Effects of Evolving Surface Contamination on Spacecraft Charging," Proc of $38^{\text {th }}$ AIAA Meeting on Aerospace Sci., (Reno, NV, 2000).

[17] E. Mullen and M. Gussenhoven, "Results of Space Experiments: CRRES," in R.N. DeWitt, D. Duston, and A.K. Hyder (eds.) The Behavior of Systems in the Space Environment, pp. 605-654, (Kluwer Academic Publishers, 1993).

[18] A.R. Frederickson, E.G. Mullen, K.J. Kerns and P.A. Robinson, "The CRRES IDM Spacecraft Experiment for Insulator Discharge Pulses,” IEEE Trans. Nuc. Phys. Vol. 40, no. 2, pp. 233-241, 1993.

[19] Nelson W. Green, A. Robb Frederickson and J.R. Dennison, "Charge Storage Measurements of Resistivity for Dielectric Samples from the CRRES Internal Discharge Monitor," Proc. of $9^{\text {th }}$ Spacecraft Charging Tech. Conf., (Epochal Tsukuba, Tsukuba, Japan, April 4-8, 2005).

[20] A. R. Frederickson and D. H. Brautigam, "Mining CRRES IDM Pulse Data and CRRES Environmental Data to Improve Spacecraft Charging/Discharging Models and Guidelines," Final Report: NASA SEE Program Contract No. NAS7-1407, Task Order 10676, 2003. 
[21] C. M, Swenson, B., A., Thompson, D., Fish, C, "Calibrating the Floating Potential Measurement Unit," Proc. of $8^{\text {th }}$ Spacecraft Charging Tech. Conf., (NASA Marshall Space Flight Center, Huntsville, Al, Oct. 2003).

[22] C. Swenson, D. Thompson, C. Fish, "The Floating Potential Measurement Unit," Proc. of $41^{\text {st }}$ Aerospace Sci. Meeting, January 2003, Paper AIAA-2003-1081.

[23] D. C. Ferguson, D. B. Snyder, R. Carruth, Report of the Joint Workshop of the Space Station Freedom Plasma Interactions and Effects Working Group, the Space Station Freedom Plasma Working Group, and the Space Station Freedom EMI/EMC and Electromagnetic Effects Working Group, 1990.

[24] S. Koontz, M. Eden, W. Spetch, T. Keeping, P. Dalton, “Assessment and Control of Spacecraft Charging Risks on the International Space Station," Proc. of 8th Spacecraft Charging Tech. Conf., (NASA Marshall Space Flight Center, Huntsville, Al, October 2003).

[25] M.R. Carruth Jr., T. Schneider, M. McCollum, M. Finckenor, R. Suggs, D. Ferguson, I. Katz, R. Mikatarian, J. Alred, and C. Pankop, "ISS and space environment interactions without operating plasma contactor,", Proc. of $39^{\text {th }}$ AIAA Aerospace Sci. Meeting, Reno, Nevada, Jan. 8-11, 2001, Paper AIAA-2001-0401.

[26] J. Minow, "Summary of the 2006 to 2010 FPMU Measurements," Proc. of $11^{\text {th }}$ Spacecraft Charging Tech. Conf., (Albuquerque, NM, September 20-24, 2010).

[27] M.R. Carruth, T. Schneider, M. McCollum, M. Finckenor, R. Suggs, D. Ferguson, I. Katz, R. Mikatarian, J. Alred, H. Barsamian, J. Kern, S. Koontz, and J.F. Roussel, "Plasma Charging of the International Space Station,” 2002, IAS Paper IAC-02-T.2.05.

[28] J.J. Osborne, I.L. Harris, G.T. Roberts and A.R. Chambers, "Satellite and Rocket-borne Atomic Oxygen Sensor Techniques," Rev. Sci. Instrum., vol. 72, no. 11, pp. 4025-4041, 2001.

[29] S. L. Koontz, L. L. Leger, S. L. Rickman, C. L. Hakes, D. T. Bui, D. E. Hunton and J. B. Cross, "Oxygen Interactions with Materials IIIMission and Induced Environments,” J. Spacecraft Rockets, vol. 32, no. 3, pp. 475-482, 1995.

[30] "K. K. de Groh, B. A. Banks, A. Guo, C. C. Ashmead, G. G. Mitchell and G. T. Yi, "MISSE 6 Polymers Atomic Oxygen Erosion Data," National Space \& Missile Materials Symposium (NSMMS), (Scottsdale, AZ, June 28 - July 1, 2010).

[31] B.A. Banks, S.K. Miller, D.L. Waters, "Materials International Space Station Experiment-6 (MISSE-6) Atomic Oxygen Fluence Monitor Experiment, NASA/TM-2010-216755, NASA Glenn Res. Center, Cleveland, OH, 2010.

[32] P. J. Codella, The Oxidation of Silver Thin films by Atomic Oxygen, $\mathrm{PhD}$ Dissertation, Utah State University, Logan, UT, 1977.

[33] D. Hastings, and H. Garrett, Spacecraft-environment Interactions, Cambridge University Press, 1996.

[34] A. Evans and J.R. Dennison, "The Effects of Surface Modification on Spacecraft Charging Parameters," submitted to IEEE Transaction on Plasma Science, 2011.

[35] RC Hoffmann and JR Dennison, "Methods to Determine Total ElectronInduced Electron Yields Over Broad Range of Conductive and Nonconductive Materials," submitted to IEEE Transaction on Plasma Science, 2011.

[36] K.L. Bedingfield, R.D. Leach and M.B. Alexander,: "Spacecraft System Failures and Anomalies Attributed to the Natural Space Environment." NASA Ref. Pub. 1390, NASA MSFC, 1996.

[37] R.D. Leach, and M.B. Alexander: "Failures and Anomalies Attributed to Spacecraft Charging," NASA Ref. Pub. 1354, NASA Marshall Space Flight Center, November 1994.

[38] M.J. Mandell, P.R. Stannard and I. Katz, "NASCAP Programmer's Reference Manual,” NASA LRC, 1993.

[39] M. Mandell, "NASCAP-2K - An Overview"," Proc. of $8^{\text {th }}$ Spacecraft Charging Tech. Conf., (NASA Marshall Space Flight Center, Huntsville, Al, October 2003).

[40] J.R. Dennison and R.C. Hoffmann, "Effects on Spacecraft Charging of Modification of Materials by Space Environment Interactions," Proc. of $11^{\text {th }}$ Spacecraft Charging Tech. Conf. (Albuquerque, NM, September 2024, 2010).

[41] Mengu Cho, "Spacecraft Charging Analysis of Large GEO Satellites Using MUSCAT," Proc. of $11^{\text {th }}$ Spacecraft Charging Tech. Conf., (Albuquerque, NM, September 20-24, 2010).

[42] L. Gamble, J. R. Dennison, B. Wood, J. Herrick, and J. S. Dyer; "Calculation of Spectral Degradation due to Contaminant Films on Infrared and Optical Sensors," Proc. SPIE-The International Soc. Optical Eng. vol. 4774, pp. 111-118, Optical System Contamination:
Effects, Measurements, and Control VII, Philip T. Chen; O. Manuel Uy; Eds. (2002).

[43] R.C. Hoffmann and J.R. Dennison, "Methods to Determine Total Electron-Induced Electron Yields Over Broad Range of Conductive and Nonconductive Materials," Proc. of $11^{\text {th }}$ Spacecraft Charging Tech. Conf. (Albuquerque, NM, September 20-24, 2010).

[44] A.R. Frederickson, C. E. Benson and J. F. Bockman, "Measurement of Charge Storage and Leakage in Polyimides," Nuclear Instrum. Methods in Phys. Res. B, pp. 454-60, 2003.

[45] ASTM D 257-99, "Standard Test Methods for DC Resistance or Conductance of Insulating Materials," 1999.

[46] J. L. Hodges, R. C. Hoffmann and J.R. Dennison, "In Situ Measurements of Electron Beam Induced Surface Voltage of Insulators," Proc. of $11^{\text {th }}$ Spacecraft Charging Tech. Conf., (Albuquerque, NM, September 20-24, 2010).

[47] D.C. Marvin, T.B. Stewart, G.S. Arnold, D.F. Hall, R.C. Young Owl, W.C. Hwang, and H.D. Marten, "Photochemical Spacecraft SelfContamination: Laboratory Results and Systems Impacts,” J. Spacecraft and Rockets, vol. 26, pp. 358-367, 1989.

[48] B. E. Wood, W. T. Bertrand, R. J. Bryson, B. L. Seiber, P. M. Balco, and R. A. Cull, "Surface Effects of Satellite Material Outgassing Products," Journal of Thermophysics and Heat Transfer, vol. 2, no. 4, pp. 289-295, 1988.

[49] P.D. Thomas, Michael C. Fong, and K.L. Neir, "Return Flux of Neutral and Charged Particles in Geosynchronous Orbit”, Proc. SPIE-The International Soc. Optical Eng., vol. 3427, pp. 290-301, Optical System Contamination: Effects, Measurements, and Control, Philip T. Chen; William E. McClintock, Gary J. Rottman; Eds. (1998).

[50] A.R. Frederickson and J.R. Dennison, "Measurement of Conductivity and Charge Storage in Insulators Related to Spacecraft Charging," IEEE Trans. Nuclear Sci., vol. 50, no. 6, pp. 2284-2291 2003.

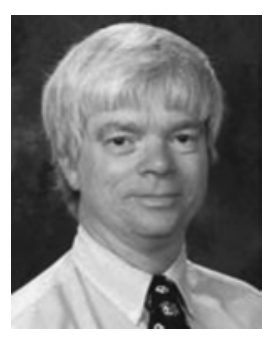

J. R. Dennison received the B.S. degree in physics from Appalachian State University, Boone, NC, in 1980, and the M.S. and Ph.D. degrees in physics from Virginia Polytechnic Institute and State University (Virginia Tech), Blacksburg, in 1983 and 1985, respectively. He was a Research Associate with the University of Missouri-Columbia before moving to Utah State University, in 1988. He is currently a Professor of physics with USU where he leads the Materials Physics Group. He has worked in the area of electron scattering for his entire career and has focused on the electron emission and resistivity of materials related to spacecraft charging for the last two decades.

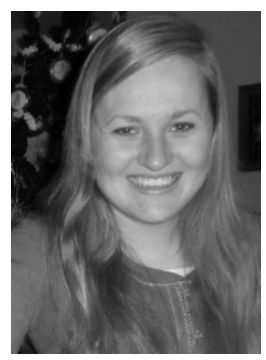

Amberly Evans is a senior dual physics and chemistry major at Utah State University in Logan, UT. She has worked with the Materials Physics Group for four years on electron emission, luminescence and resistivity studies and on MISSE retrieval and post-flight analysis of SUSpECS. Much of her work has focused on optical scattering of spacecraft materials.

Danielle Fulmer is a sophomore biology major at Utah State University in Logan, UT. She has worked for the Materials Physics Group for one year on post-flight analysis of SUSPECS.

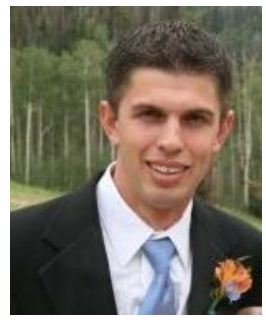

Joshua L. Hodges received a BS in Mechanical and Aerospace Engineering in 2006 and an MS in Physics in 2011 from Utah State University in Logan, UT. He worked with the USU GAS team on the design, construction and pre-flight testing of SUSpECS and with the Materials Physics Group on MISSE retrieval and post-flight analysis of SUSpECS. He is currently a Service Life Monitoring Program Manager with the T-38 Structural Analysis Group at Hill Air Force Base in Ogden, UT. 